\title{
Measuring the vibration of a brush cutter in different operation modes
}

\author{
László, H. E. \\ Corvinus University of Budapest, Faculty of Horticulture Sciences, Technical Department, \\ 1118 Budapest, Villányi út 29-43., Hungary \\ Imperial College London, Faculty of Medicine, Department of Epidemiology and Biostatistics, \\ W2 1PG London, St Mary's Campus, Norfolk Place, United Kingdom
}

\begin{abstract}
Summary: The vibration load of a hand-held machine depends on many factors not defined in the ISO 5349:2001 standard about the measurements and evaluation of human exposure to hand-transmitted vibration. In this study, the effect of different operation modes on the vibration emission of a brush cutter was investigated. The frequency weighted r.m.s. acceleration was measured at the front (left) and rear (right) handle in three orthogonal directions according to ISO 5349 (2001). Two set of measurements were performed with three subjects for idling and cutting operations. In addition, the acceleration was measured with two holding positions, i.e. the cutting head is tilted by $45^{\circ}$ to the left and tilted by $45^{\circ}$ to the right. The standard vibration evaluation method, with the cutting head parallels to the ground, significantly under-estimated the vibration emission of the tilted tool to the left and right. The results suggest that the use of different holding positions would improve the reliability of the standard method of assessing the vibration of hand-held tools.
\end{abstract}

Keywords: hand-arm vibration, hand-held tool, brush cutter, operation mode, vibration acceleration

\section{Introduction}

Extended exposures of the hand and fingers to vibration can result various disorders like finger blanching, numbness at the hand, tingling, reduced muscle activity or bone and joints problems (Griffin, 1990). The source of hand-transmitted vibration is often a hand-held tool that is widely used in gardening or landscape architecture. Vibration induced injuries at the hand-arm system, have been widely studied among forestry workers using chain saws (Sutinen et al., 2006; Färkkilä et al., 1988; Bovenzi, 2008). The operators of hand-held power tools are exposed various levels of hand-arm vibration at the tool-hand interface. Risks can be assessed either without performing measurements, by referring to information available from manufacturers or certified databases, or by means of measurements carried out in accordance with methodology defined in specific ISO-EN standards. The EU Physical Agents Directive on human exposure to vibration published on 22 June 2002, defines "the minimum health and safety requirements" for the exposure of workers to the risks arising from vibration. The Directive sets two limits for hand-transmitted vibration: the exposure action value is $2.5 \mathrm{~ms}^{-2}$ and the exposure limit value is $5.0 \mathrm{~ms}^{-2}$ (Directive 2002/44/EC).

The acceleration values for hand held tools such as brush cutters have been measured at the handle of a tool according to ISO 5349:2001 in order to evaluate their vibration. Several factors might contribute to the vibration transmitted to the hand like operator's posture, working conditions, indi-

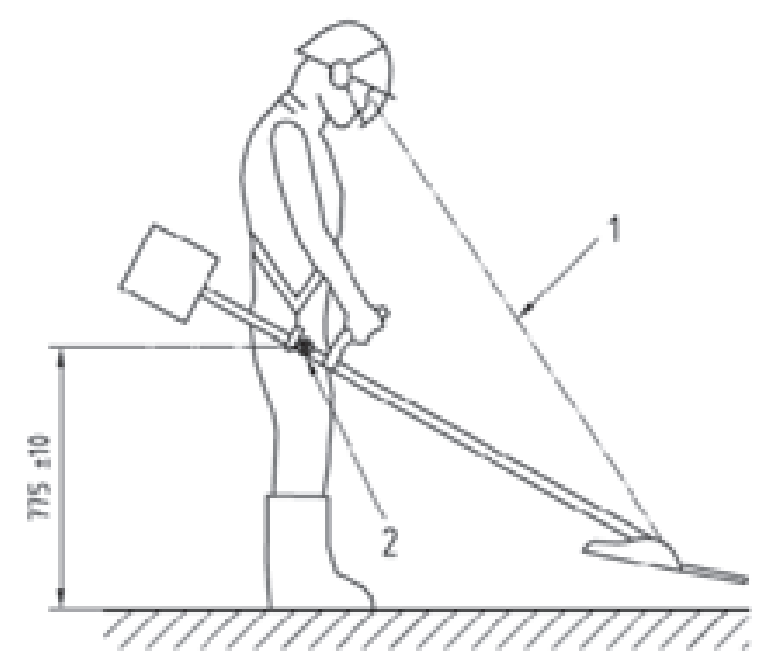

Figure 1. Operating position (ISO 22867:2008; 1-operator's view towards the cutting tool, 2-centre of gravity)

vidual factors, etc. (ISO 5349:2001). It is therefore important to determine the standardised working conditions in which the measurement is carried out. As a general guidance, the machine shall be held in a manner consistent with day-along use of the machine during the vibration measurement. Powered brush cutters shall be held upright as shown in Figure 1 (ISO 22867:2008). However this is not a representative position for example in case of hillside cutting that is common especially during motorway maintenance. Very few studies have been carried out to investigate the effect of the operation 
conditions of a horticultural tool on its vibration emission. Mallick (2008) studied three handle-hand positions and three sway angles of a grass trimmer in terms of hand-arm vibration and found that the operation mode (i.e. engine speed, nylon thread length, sway angle) has a significant effect on the vibration transmitted to the hand. The holding position of the tool could result $35 \%$ difference in hand-transmitted vibration. In another study it was found that the optimal operating parameters of a grass trimmer, in terms of minimising the hand-arm vibration, are depend on the engine speed, the length of the nylon thread length and the handle material (Mallick, 2009). Tudor (1996) studied the effect of different holding positions, handle design and nylon thread type of a grass trimmer on the hand-transmitted vibration and found, that the handle design could change the vibration transmitted to the hand by changing the forces affecting on the human body. As a result, in real working conditions the vibration load of a hand-held tool might differ from the manufacturers' emission data that was obtained according to ISO 5349:2001.

In this study the effect of the holding position on the vibration load was investigated by using a powered brush cutter during idling and cutting operations. The tilted position of the cutting plane was found to be an important representation of real working conditions.

\section{Materials and methods}

\section{Test equipment}

Trimmers and brush cutters are small machines that use a rapidly spinning plastic line or a metal knife to break off or cut the plants. Depending on the engine size, location, shaft design or handle shape design, there are several variations of trimmers and cutters. In this study, the hand-transmitted vibration was evaluated using a powered back-pack type brush cutter. Table 1 summarises the technical parameters of the machine. The measurements were performed using similar equipment and procedures to those specified in ISO 5349:2001. The vibration transmitted to the hand has been measured using a light weight tri-axial accelerometer (Svantek SV 3023M2) that was mounted on an aluminium hand-arm adapter (Svantek SV 50). Svan 958 Four Channels Sound and Vibration Analyser has been used for data acquisition. The data was analysed using SvanPC software (version 2.7.18).

Table 1 Technical details of the brush cutter.

\begin{tabular}{|l|l|l|l|}
\hline \multicolumn{1}{|c|}{$\begin{array}{c}\text { Production } \\
\text { code }\end{array}$} & \multicolumn{1}{|c|}{$\begin{array}{c}\text { Partner } \\
\text { T 330 Pro }\end{array}$} & \multicolumn{1}{|c|}{ Handle type } & \multicolumn{1}{c|}{ J } \\
\hline $\begin{array}{l}\text { Engine } \\
\text { displacement }\end{array}$ & $32 \mathrm{~cm}^{3}$ & Type of shaft & Straight \\
\hline Power & $\begin{array}{l}0.7 \mathrm{~kW} / 7000 \\
\mathrm{rmp}\end{array}$ & Working width & $43 \mathrm{~cm}$ \\
\hline Weight & $5.9 \mathrm{~kg}$ & $\begin{array}{l}\text { Noise (LPA/ } \\
\text { LWA) }\end{array}$ & $\begin{array}{l}85.6 / 105.7 \\
\mathrm{~dB}(\mathrm{~A})\end{array}$ \\
\hline Idling speed & $3000 \mathrm{~min}^{-1}$ & $\begin{array}{l}\text { Vibration(front/ } \\
\text { back) idling }\end{array}$ & $11.8 / 6.8 \mathrm{~ms}^{-2}$ \\
\hline Fuel tank volume & 0.2251 & $\begin{array}{l}\text { Vibration(front/ } \\
\text { back) cutting }\end{array}$ & $8.7 / 8.6 \mathrm{~ms}^{-2}$ \\
\hline
\end{tabular}

\section{Test procedure}

The hand-held adaptor was placed in the palm; therefore it was directly contacted with the vibration surface (see Figure 2). The transducer was inserted between the middle and index fingers. The accelerations (frequency weighted r.m.s., peak, peak-to-peak, maximum values) at the tool handles were recorded along the $x$-, $y$ - and $z$ - direction simultaneously for left and right hands according to ISO 5349:2001. The vibration transmitted to the users' hands was evaluated for idling and cutting operations (i.e. at 3000 and $7000 \mathrm{rmp}$ respectively) in the nominal frequency range of $5.6 \mathrm{~Hz}$ to $1400 \mathrm{~Hz}$. The tool was held in three positions: (i) with the cutting head horizontal, (ii) with the cutting head tilted by $45^{\circ}$ to the left and (iii) with the cutting head tilted by $45^{\circ}$ to the right (see Figure 3 ). Three, average build male subject with relevant experience operated the tools. Based on preliminary tests, $20 \mathrm{~s}$ measurement time was found to be representative for the tools' acceleration. Each measurement was performed two times.

\section{Theoretical considerations}

The measurement, evaluation and assessment of risks associated with hand-transmitted vibration are mostly based on guidelines and dose-response relationship provided in ISO5349 (2001). The responses of the human body to vibration are highly dependent on the frequency of vibration, therefore frequency weighting, $W_{h}$ is applied during the evaluation. The r.m.s. frequency weighted vibration acceleration, $a_{h w}$ is calculated as (ISO 5349, 2001):

$$
a_{h w}=\left[\sum_{i=1}^{n}\left(W_{h i} a_{h i}\right)^{2}\right]^{1 / 2}
$$

where $W_{h i}$ is the weighting factor for the $i$ the one-third-octave band, $a_{h i}$ is the r.m.s. acceleration in the $i$ the one-third octave band in $\mathrm{ms}^{-2}$ and $n$ is the number of the one-thirdoctave band considered. The weighted r.m.s. acceleration values, $a_{h w}$ of the three subjects and two repeats were averaged along the $\mathrm{x}-, \mathrm{y}$ - and $\mathrm{z}$ - direction for each condition. The mean vibration total value, $\left(\mathrm{ms}^{-2}\right.$ r.s.s.) was calculated with the following formula:

$$
\overline{a_{h v}}=\left[\overline{a_{h w x}^{2}}+\overline{a_{h w y}^{2}}+\overline{a_{h w z}^{2}}\right]^{1 / 2}
$$

where and are the mean weighted r.m.s. accelerations in $\mathrm{ms}^{-2}$ for $x$-, $y$ - and $z$-axes respectively.

\section{Results and discussion}

Table 2 shows the mean weighted r.m.s. accelerations and coefficient of variations $(\mathrm{CoV})$ for each operating conditions. Comparing the mean weighted r.m.s. accelerations in Table 2 it can be seen that generally the vibration was greater dur- 

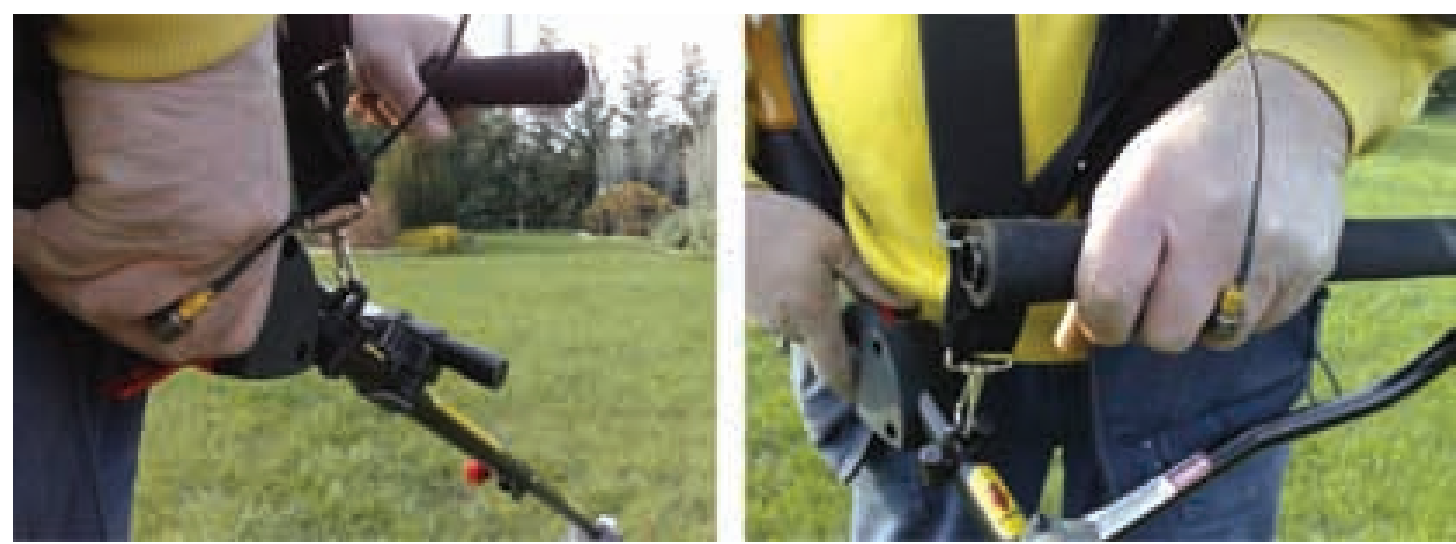

Figure 2. The position of the accelerometer at the back and at the front handle
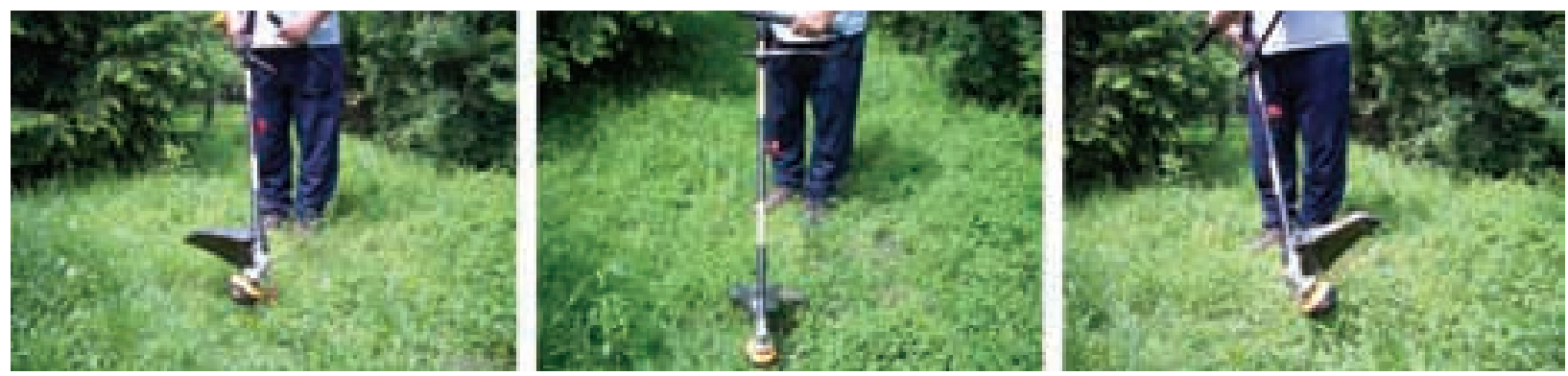

Figure 3. The three holding positions of the tool

ing cutting operation. This could be a result of the different engine speed during idling and cutting operations that correlates with the tool vibration emission (ISO 5349:2001).

Table 2. Weighted r.m.s. accelerations in three orthogonal directions measured at the front and rear handle of a hedge trimmer during idling and cutting operation. Mean of six measurements

\begin{tabular}{|c|c|c|c|c|c|c|c|}
\hline \multirow[b]{2}{*}{$\begin{array}{c}\text { Position } \\
\text { of the } \\
\text { accelero- } \\
\text { meter }\end{array}$} & \multirow[b]{2}{*}{$\begin{array}{c}\text { Ortho- } \\
\text { gonal } \\
\text { direction }\end{array}$} & \multicolumn{3}{|c|}{ IDLING } & \multicolumn{3}{|c|}{ CUTTING } \\
\hline & & $\begin{array}{c}\text { r.m.s. } \\
\text { accelera- } \\
\text { tion } \\
\left(\mathrm{ms}^{-2}\right) \\
\end{array}$ & $\mathrm{CoV}$ & $\bar{a}_{h v}$ & $\begin{array}{c}\text { r.m.s. } \\
\text { accelera- } \\
\text { tion } \\
\left(\mathrm{ms}^{2}{ }^{2}\right) \\
\end{array}$ & $\mathrm{CoV}$ & $\bar{a}_{h v}$ \\
\hline \multirow{3}{*}{$\begin{array}{l}\text { Front } \\
\text { handle }\end{array}$} & $\mathrm{x}$ & 2.753 & 0.128 & \multirow{3}{*}{4.205} & 2.228 & 0.032 & \multirow{3}{*}{3.922} \\
\hline & $\mathrm{y}$ & 2.958 & 0.082 & & 3.115 & 0.045 & \\
\hline & $\mathrm{z}$ & 1.161 & 0.129 & & 0.847 & 0.061 & \\
\hline \multirow{3}{*}{$\begin{array}{l}\text { Front } \\
\text { handle L }\end{array}$} & $\mathrm{x}$ & 2.920 & 0.061 & \multirow{3}{*}{4.093} & 2.458 & 0.035 & \multirow{3}{*}{3.911} \\
\hline & $\mathrm{y}$ & 2.765 & 0.062 & & 2.900 & 0.009 & \\
\hline & $\mathrm{z}$ & 0.762 & 0.135 & & 0.921 & 0.044 & \\
\hline \multirow{3}{*}{$\begin{array}{l}\text { Front } \\
\text { handle R }\end{array}$} & $\mathrm{x}$ & 4.117 & 0.016 & \multirow{3}{*}{5.095} & 5.089 & 0.006 & \multirow{3}{*}{5.738} \\
\hline & $\mathrm{y}$ & 2.731 & 0.052 & & 2.227 & 0.023 & \\
\hline & $\mathrm{z}$ & 1.244 & 0.351 & & 1.440 & 0.042 & \\
\hline \multirow{3}{*}{$\begin{array}{l}\text { Back } \\
\text { handle }\end{array}$} & $\mathrm{x}$ & 2.940 & 0.035 & \multirow{3}{*}{3.557} & 2.931 & 0.029 & \multirow{3}{*}{3.922} \\
\hline & $\mathrm{y}$ & 0.622 & 0.025 & & 0.691 & 0.022 & \\
\hline & $\mathrm{z}$ & 1.904 & 0.017 & & 2.513 & 0.066 & \\
\hline \multirow{3}{*}{$\begin{array}{l}\text { Back } \\
\text { handle L }\end{array}$} & $\mathrm{x}$ & 2.718 & 0.005 & \multirow{3}{*}{3.587} & 3.492 & 0.004 & \multirow{3}{*}{4.298} \\
\hline & $\mathrm{y}$ & 0.759 & 0.038 & & 0.787 & 0.018 & \\
\hline & $\mathrm{z}$ & 2.215 & 0.062 & & 2.379 & 0.040 & \\
\hline \multirow{3}{*}{$\begin{array}{l}\text { Back } \\
\text { handle R }\end{array}$} & $\mathrm{x}$ & 4.162 & 0.055 & \multirow{3}{*}{4.779} & 5.986 & 0.018 & \multirow{3}{*}{$6.44 \mathrm{C}$} \\
\hline & $\mathrm{y}$ & 0.606 & 0.045 & & 0.675 & 0.052 & \\
\hline & $\mathrm{z}$ & 2.270 & 0.010 & & 2.301 & 0.006 & \\
\hline
\end{tabular}

Note: $\mathrm{L}=$ tilted by $45^{\circ}$ to the left, $\mathrm{R}=$ tilted by $45^{\circ}$ to the right
The Wilcoxon matched-pairs signed ranks tests revealed that the mean weighted r.m.s. acceleration values of the six runs in each holding position and operation was generally significantly $(\mathrm{p}<0.05)$ lower at the rear handle than at the front one (Table 3) except during cutting while the cutting attachment was tilted to the right. As a result, the hand holding the front handle is more exposed to vibration. Therefore, the vibration emission of this tool should be evaluated at the front handle otherwise the standardised method might underestimate the vibration load of this machine. The results show that for the front handle, the vibration at the $x$ and $y$-axes were dominant, while for the rear handle, the greatest accelerations occurred in the $x$ and $z$ directions. This indicates the importance of measuring the vibration at all three directions simultaneously to calculate the vibration total value of a backpack brush cutter.

Significant differences $(\mathrm{p}<0.05)$ in mean weighted r.m.s. acceleration at each axes have been found for the different holding positions in both operations (see Table 3). For the front handle, the differences in acceleration occurred mainly at the $x$ and $z$ direction, but for the rear handle, differences in acceleration were significant in all directions independent of the engine speed. Generally, the vibration emission was greater when the measurement was performed by holding the brush cutter in 
a tilted position than holding it upright. The differences in were particularly significant in case of the tool tilted to the right compared to the values in normal position. For example, $2.527 \mathrm{~ms}^{-2}$ difference in mean weighted acceleration was observed during cutting operation at the rear handle between the upright position and the tilted position to the right. Therefore, the standard vibration evaluation method, with cutting head plane is parallel to the ground, does not indicate accurately the vibration exposure of the tool. The difference in acceleration might be the result of the different motor positions; an unbalanced rotation could increase the vibration of the tool. Another explanation for the different values of handtransmitted vibration might arise from the different gripping force of the tool handle. The position of the wrist directly affects the position of the hand adaptor, therefore the measured vibration transmitted to the hand; the more the wrist position differ from neutral, the greater the gripping force (Tudor, 1996). An increased grip leads to increase the stiffness of the hand-arm system as well, that could result an increase in the vibration transmitted to the hand (Pyykkö et al., 1976).

Table 3 Statistical significance ( $p$-values) of differences in mean r.m.s. accelerations obtained with different operation (i.e. idling and cutting) and holding positions (Wilcoxon matched-pairs signed ranks tests).

\begin{tabular}{|c|c|c|c|c|c|c|c|}
\hline $\begin{array}{c}\text { Ort- } \\
\text { hogonal } \\
\text { direction }\end{array}$ & $\begin{array}{l}\text { Handle } \\
\text { position }\end{array}$ & $\begin{array}{l}\text { Front } \\
\text { handle }\end{array}$ & $\begin{array}{c}\text { Front } \\
\text { handle I }\end{array}$ & $\begin{array}{c}\text { Front } \\
\text { handle } r\end{array}$ & $\begin{array}{c}\text { Rear } \\
\text { handle }\end{array}$ & $\begin{array}{c}\text { Rear } \\
\text { handle I }\end{array}$ & $\begin{array}{c}\text { Rear } \\
\text { handle } r\end{array}$ \\
\hline \multirow{3}{*}{$\mathrm{X}$} & $\begin{array}{l}\text { front } \\
\text { handle }\end{array}$ & & $\begin{array}{l}0.345 \\
0.028\end{array}$ & $\begin{array}{l}0.028 \\
0.028\end{array}$ & $\begin{array}{l}0.249 \\
0.028\end{array}$ & & \\
\hline & $\begin{array}{l}\text { front } \\
\text { handle L }\end{array}$ & & & $\begin{array}{l}0.028 \\
0.028\end{array}$ & & $\begin{array}{l}0.075 \\
0.028\end{array}$ & \\
\hline & $\begin{array}{l}\text { front } \\
\text { handle } \mathrm{R}\end{array}$ & & & & & & $\begin{array}{l}0.463 \\
0.028\end{array}$ \\
\hline \multirow{3}{*}{$\mathrm{y}$} & $\begin{array}{l}\text { front } \\
\text { handle }\end{array}$ & & $\begin{array}{l}0.173 \\
0.028\end{array}$ & $\begin{array}{l}0.173 \\
0.028\end{array}$ & $\begin{array}{l}0.028 \\
0.028\end{array}$ & & \\
\hline & $\begin{array}{l}\text { front } \\
\text { handle L }\end{array}$ & & & $\begin{array}{l}0.917 \\
0.028\end{array}$ & & $\begin{array}{l}0.028 \\
0.028\end{array}$ & \\
\hline & $\begin{array}{l}\text { front } \\
\text { handle } \mathrm{R}\end{array}$ & & & & & & $\begin{array}{l}0.028 \\
0.027\end{array}$ \\
\hline \multirow{3}{*}{$\mathrm{Z}$} & $\begin{array}{l}\text { front } \\
\text { handle }\end{array}$ & & $\begin{array}{l}0.028 \\
0.116\end{array}$ & $\begin{array}{l}0.600 \\
0.028\end{array}$ & $\begin{array}{l}0.028 \\
0.028\end{array}$ & & \\
\hline & $\begin{array}{l}\text { front } \\
\text { handle L }\end{array}$ & & & $\begin{array}{l}0.075 \\
0.028\end{array}$ & & $\begin{array}{l}0.028 \\
0.028\end{array}$ & \\
\hline & $\begin{array}{l}\text { front } \\
\text { handle R }\end{array}$ & & & & & & $\begin{array}{l}0.028 \\
0.028\end{array}$ \\
\hline \multirow{2}{*}{$\mathrm{X}$} & $\begin{array}{l}\text { rear } \\
\text { handle }\end{array}$ & & & & & $\begin{array}{l}0.028 \\
0.028\end{array}$ & $\begin{array}{l}0.028 \\
0.028\end{array}$ \\
\hline & $\begin{array}{l}\text { rear } \\
\text { handle L }\end{array}$ & & & & & & $\begin{array}{l}0.028 \\
0.028\end{array}$ \\
\hline \multirow{2}{*}{$\mathrm{y}$} & $\begin{array}{l}\text { rear } \\
\text { handle }\end{array}$ & & & & & $\begin{array}{l}0.028 \\
0.028\end{array}$ & $\begin{array}{l}0.028 \\
0.463\end{array}$ \\
\hline & $\begin{array}{l}\text { rear } \\
\text { handle L }\end{array}$ & & & & & & $\begin{array}{l}0.028 \\
0.028\end{array}$ \\
\hline \multirow{2}{*}{$\mathrm{z}$} & $\begin{array}{l}\text { rear } \\
\text { handle }\end{array}$ & & & & & $\begin{array}{l}0.028 \\
0.075\end{array}$ & $\begin{array}{l}0.028 \\
0.046\end{array}$ \\
\hline & $\begin{array}{l}\text { rear } \\
\text { handle L }\end{array}$ & & & & & & $\begin{array}{l}0.028 \\
0.046\end{array}$ \\
\hline
\end{tabular}

Note: normal letter p-values are for idling operation, bold letter p-values are for cutting operation.
The variability in the acceleration values during idling (coefficient of variation, $\mathrm{CoV}$, in the range 0.005 to 0.351 ) was generally greater to those during cutting $(\mathrm{CoV}$ in the range of 0.004 to 0.066 ). The reason of this phenomenon could be the different applied force on the handle; during cutting operation, the subjects grasp the handle with a higher force in order to direct the tool. As a result, the hand adaptor with the accelerometer was kept in a fixed position.

\section{Conclusions}

The vibration emission of a powered back-pack type brush cutter has been evaluated under different operating conditions. Different accelerations have been measured during idling and cutting. Significant differences in vibration were observed at the front and rear handle. The necessity of evaluating the vibration exposure of a powered brush cutter at three orthogonal directions was shown.

With different holding positions, significant differences were found in the acceleration of the tool. Generally, the standard position underestimated the vibration load of the brush cutter measured in tilted position to the right and left. Therefore the standard test does not provide accurate predictions of the vibration exposure when the brush cutter is held in a tilted position. The currently standardised method for measuring the vibration exposure of a brush cutter could be improved by measuring the vibration at different holding positions that is similar to real working conditions.

\section{References}

Directive 2002/44/EC, of 25 June 2002. On the minimum health and safety requirements regarding the exposure of workers to the risks arising from physical agents (vibration). Official Journal of the European Communities. 13-17.

Griffin, M.J. (1990): Handbook of Human Vibration, London: Academic Press.

ISO 22867: 2008: Forestry machinery - Vibration test code for portable hand-held machines with internal combustion engine - Vibration at the handles (ISO 22867:2004, including Cor 1:2006). International Organization for Standardization. Geneva, Switzerland.

ISO 5349:2001: Mechanical Vibration. Measurement and evaluation of human exposure to hand-transmitted vibration. International Organization for Standardization. Geneva, Switzerland.

Mallick Z. (2008): Optimization of operating parameters for a backpack type grass trimmer. International Journal of Industrial Ergonomics. 38: 101-110.

Mallick, Z. (2009): Optimization of the operating parameters of a grass trimming machine. IN PRESS Applied Ergonomics, doi:10.1016/j. apergo.2009.07.010

Pyykkö, I., Färkkilä. M., Toivanen, J., Korhonen, O., St Hyvarinen, J. (1976): Transmission of vibration in the hand - arm system with special reference to changes in compression force and acceleration. Scandinavian Journal of Work Environment and Health, 2: 87-95.

Tudor A.H. (1996): Hand-arm vibration: Product design principles. Journal of Safety Research. 27 (3): 157-162. 